\title{
Analysis on three phase cascaded H-bridge multilevel inverter based on sinusoidal and third harmonic injected pulse width modulation via level shifted and phase shifted modulation technique
}

\author{
A. Shamsul Rahimi A. Subki ${ }^{1}$, Zahariah Manap², Mohd Zaidi Tumari ${ }^{3}$, Aiman Zakwan Jidin ${ }^{4}$, \\ Shahrizal Saat ${ }^{5}$, Amar Faiz Zainal Abidin ${ }^{6}$, Muhammad Salihin Saealal ${ }^{7}$ \\ 1,2,4,5,6 Department of Electronic \& Computer Eng. Technology, Faculty of Electrical and Electronic Engineering \\ Technology, University Teknikal Malaysia Melaka, Melaka, Malaysia \\ ${ }^{3,7}$ Department of Electrical Eng. Technology, Faculty of Electrical and Electronic Engineering Technology, University \\ Teknikal Malaysia Melaka, Melaka, Malaysia \\ ${ }^{2}$ Center for Telecommunication Research \& Innovation (CeTRI), University Teknikal Malaysia Melaka, Melaka,
} Malaysia

\begin{tabular}{l} 
Article Info \\
\hline Article history: \\
Received Jan 13, 2020 \\
Revised Jan 16, 2021 \\
Accepted Feb 1, 2021 \\
\hline Keywords: \\
Cascaded H-bridge MLI \\
Level-shifted PWM \\
Phase-shifted PWM \\
Sinusoidal PWM \\
Third harmonic injection PWM
\end{tabular}

\begin{abstract}
This work proposes a comparative analysis of sinusoidal and third harmonic injected reference signal modulation accompany with level-shifted PWM technique named as phase disposition (LSPD), phase opposition disposition (LSPOD), and alternate phase opposition disposition (LSAPOD) and phaseshifted PWM technique. Switching pulses from both reference signal and PWM technique have been fed into three phase eleven level cascaded $\mathrm{H}$ bridge multilevel inverter (CHBMLI) fed on a resistive-inductive load with the modulation depth (MD) set to varied from $80 \%$ to $100 \%$. For voltage source inverter, total harmonic distortion (THD) content is critical and must be within the allowable range. To prove the feasibility of the reference signal with carrier signal schemes, the entire simulation of the modulation techniques is established and conducted via the Simulink environment. According to the analyzed result, the performance is acceptable in terms of $\%$ THDV and \%THDI values. Simulation analysis also indicates, at full modulation depth, due to higher fundamental output voltage component produces via the THIPWM modulation technique compared to the SPWM technique, this causes higher \% THDV value.
\end{abstract}

This is an open access article under the CC BY-SA license.

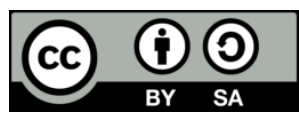

Corresponding Author:

A. Shamsul Rahimi A. Subki

Department of Electronic \& Computer Eng. Technology

University Teknikal Malaysia Melaka, Melaka, Malaysia

Email: shamsulrahimi@utem.edu.my

\section{INTRODUCTION}

In recent times, multi-level inverter (MLI) has portrayed significant interest in high power utilization due to numerous benefits. The most obvious MLI advantages are without connecting output node to the transformer and without dynamic voltage balancing circuits, MLI can yield high-power output through the utilization of semiconductor switches mainly insulated gate bipolar transistor (IGBT). Another MLI significant contribution is the harmonics distortion content of the output voltage and current along with electro-magnetic interference (EMI) decrease if the number of output levels increases [1]. The theory of inverter output voltage can be categorized into two distinctive modes, for instance, square wave output (4 
modes switching) and modified square wave or quasi-square wave output (6 modes switching) [2]. Based on the fact that for low and medium power applications, the square wave and quasi-square wave inverters can be bearable. Nonetheless, high power utilization required sinusoidal waveforms with low distorted characteristics. This causes four modes and six modes switching inverter not recommended due to remarkably low-quality waveform due to the presence of harmonic distortion [3], [4]. To apprehend this demerit, the multi-level inverter (MLI) concept which produces a multi-stepped or ladder waveform was introduced. The principle of the MLI is started based on the concept of a sinusoidal voltage step approximation. Via pulse width modulation technique, the waveform of MLI output is segregated into two high-frequency categories and low-frequency multi-stepped waveform. The output voltage waveform of MLI can be achieved by cascading connected two or more leg of an H-bridge inverter. Using low supply DC voltage rating, the objective of the MLI topologies is to generate a high-power AC voltage output by utilization switching devices that usually, these switching devices are switched sequentially via PWM pulses, giving an output pattern which consists of discrete predefined voltage steps [5], [6]. MLI usage strongly relies on the application and the frequently used MLI topologies can be group into flying capacitor (FC), neutral point clamped (NPC), and cascaded H-bridge (CHB) MLI [5]. Among these topologies, based on its modularity and simplicity to control, the CHBMLI has been attractive, and, has been effectively implemented, fabricated and commercialized [7]-[9].

Multiple topologies of pulse width modulation (PWM) based schemes have become increasingly likeable and rapidly demand more attention among researchers. PWM-based techniques are employed to produce variable frequency and voltage source. Modulation methods based on carrier signal arrangement are classed into three topologies namely, phase shift PWM (PSPWM), level shift PWM (LSPWM), and hybrid PWM modulation technique [10]-[13]. For any number of levels, aimed to reduce the voltage distortion and evenly distribute power among the connected cells, PSPWM is suitable to implement. The distortion can be hugely reduced proportionally to the number of levels and carrier signals required. Meanwhile, the LSPWM technique can be classified into an identical frequency method and an unidentical frequency method. Under the category of identical frequency, LSPWM is further divided into phase disposition [14], phase opposition and disposition, alternative phase opposition and disposition, carrier overlapping, variable amplitude [15]-[17] and hybrid techniques of carrier arrangement. To produce the switching pulses, sinusoidal and third harmonic injection reference modulating signals are used, and both are tuned to operate via a bipolar switching method. Normally, for an open-loop system, the sinusoidal reference modulation signal is chosen while for a closedloop system, the same reference with a compensating signal is selected [18]. By the injection of the thirdorder harmonics into the sine wave reference, THI reference signal with dual peak characteristic is generated. Since its similarity to the Selected Harmonic Injection method, it can implement in the same manner as sinusoidal PWM [15]. Since the THI reference signal consists of both a fundamental component and a third harmonic component, the THI reference wave is not sinusoidal and easily noticeable its dual peak characteristic. Subsequently, the peak amplitude of the fundamental component is approximately $15.5 \%$ higher in amplitude than that achieved by the sinusoidal PWM [19]. Therefore, the third harmonic PWM delivers better consumption of the DC supply voltage than the MLI SPWM does.

In this work, multicarrier based PWM techniques focusing on level-shifted PWM techniques such as phase disposition (PD), phase opposition disposition (POD), and alternate phase opposition disposition (APOD) is chosen to be compared with phase-shifted-PWM switching technique. Both the multicarrier PWM technique has been fed to 11-level cascaded H-bridge MLI as switching pulses. To determine the significant difference between PWM modulation techniques, it worth considering the effective output voltage ( $\left.\mathrm{V}_{\mathrm{RMS}}\right)$, the percentage of total harmonic distortion THD and the quality of output waveform based on crest factor (CF) and form factor (FF) ratio. The DC supply utilization for each leg between CHBMLI that use SWPM and THIPWM also will be investigated. By individually comparing Sinusoidal and Third Harmonic Injection reference signal with various multicarrier level-shifted and phase-shifted signal with the modulation depth is varied from $80 \%$ to $100 \%$, the PWM signal is generated for each leg of MLI.

\section{RESEARCH METHOD}

MLI system efficiency is directly associated with the modulation technique, which is used to regulate the output voltage (and current). Via output voltage value obtained, the calculation of MLI significant parameters such as total harmonic distortion (\% THD), output waveform quality based on the form factor and crest factor ratio and switching power losses can be performed. For voltage source inverter, the most extensively used is sinusoidal PWM (SPWM), third harmonic injection PWM (THIPWM) and space vector PWM (SVPWM) [20]. With the differences in fundamental voltage component, amplitude, and frequency that is usually a sinusoidal form in steady-state, the objective of a modulation signal is to yield a stepped waveform that is aids as an approximation of a reference signal. This can be accomplished by 
manipulating the duty ratio of the inverter components. Beside SPWM is the simplest control strategy which is used widely in the inverters, it has some disadvantages which is poor output waveform quality, weak modulation ability on active power and reactive power, very narrow linear range, higher total harmonic distortion (THD) and lowers effective utilization of DC value [11]. With the mentioned drawback of the SPWM technique, THIPWM is largely used. The performance compared to SPWM in terms of reducing harmonic content in current ripple, optimized switching sequence and increased voltage transfer ratios are tremendously better and provide a huge significant advantage. There are various types of methods for the selection of switching techniques and strategies for the CHBMLI. In this paper, multicarrier-level-shifted PWM (MC-LSPWM) and multicarrier-phase-shifted (MC-PSPWM) techniques are chosen to be compared between one another to identify and determine their attribute and significantly different when been fed into CHBMLI. For LSPWM, it comprises of various types of disposition such as phase disposition (PD), phase opposition and disposition (POD), alternative phase opposition and disposition (APOD) [21]-[23].

\subsection{Reference signal}

With sinusoidal pulse width modulation (SPWM) technique, a sinusoidal waveform is produced through filtering an output pulse waveform. By varying the amplitude and frequency of a reference or modulating signal, an improved filtered sinusoidal output waveform can be generated by utilizing a high switching frequency scheme. For the SPWM technique, instead of maintaining identical widths, it maintains the pulses in different widths where the distortion factor (DF) and lowest order harmonics (LOH) are significantly compact. In three-phase SPWM, a carrier voltage waveform is compared with three sinusoidal control voltages $\left(\mathrm{V}_{\mathrm{a}}, \mathrm{V}_{\mathrm{b}}\right.$, and $\mathrm{V}_{\mathrm{c}}$ ), which are $120^{\circ}$ out of phase with one another and the comparative levels of the waveforms are used to control the switching of the devices in each phase leg of the inverter [18]. Aside from SPWM, since the third harmonic component is not existing in three-phase systems, the Third Harmonic Injection PWM is ideal and practical for there phase MLI [13]. Sinusoidal PWM is the modest modulation scheme to understand, but it is incompetent to fully exploit the offered DC bus supply voltage which means, at lower modulation indices, one or two legs of an inverter is not fully utilized. Due to this drawback, the THIPWM strategy was developed to improve inverter performance. By injecting reference signals with a third harmonic signal, the THIPWM reference waveform is produced with dual peak characteristics. It is possible to acquire a significant amplitude surge at the output voltage without loss of quality [18], [24].

\subsection{Carrier signal arrangement}

Using a method developed as reported in [18], diverse carrier signals are created based on LevelShifted and Phase-Shifted Multicarrier PWM scheme. For both schemes, for n-level CHBMLI, all carrier signals are generated with the identical carrier frequency, $f c$. Figure 1 explained one carrier signal waveform generation via pulse generator. By further tuning of pulse amplifier, signal amplifier, and amplitude modifier module parameter, symmetrical in term of amplitude and width carrier signals can be created.

In the PSWPM scheme, the phase-shifted among any two neighbouring carrier waves with the triangular carriers having an identical frequency and same peak-peak amplitude. In order to provide an even power distribution among the CHBMLI cells, each cell is modulated independently via bipolar pulse width modulation. For $\mathrm{m}$ number voltage level, (m-1) a number of carrier signals are required and phase-shifted angle, $\theta$ is calculated as $\left(360^{\circ} / \mathrm{m}-1\right)$. In the LSPWM scheme, carrier signals extend and cover the total range of produced converter output voltage, and contain the same amplitude, Ac. For each subcategory of LSPWM, the carrier signal is classified based on multiple carriers signals the placement and disposition. For all type of disposition, as mention earlier in [14], $M_{f}$ and $M_{a}$ are chosen. LSPWM is further subdivided into phase disposition (PD), phase opposition and disposition (POD) and alternate phase opposition and disposition (APOD). Detailed of each disposition under LSPWM is as discussed in [14].

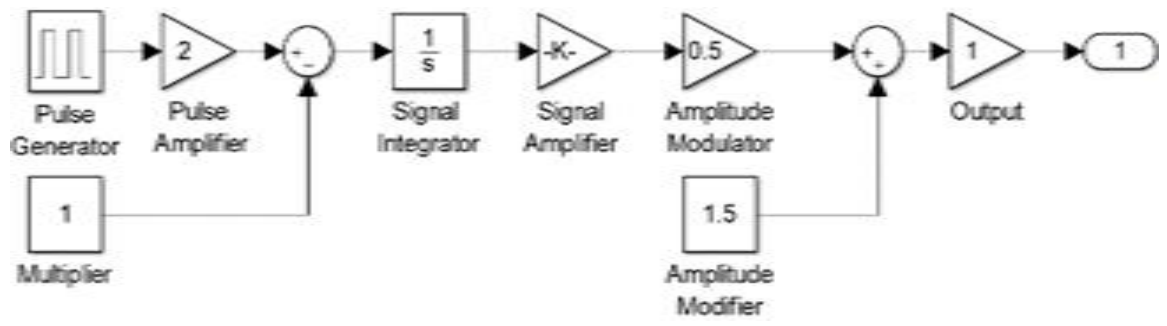

Figure 1. The module of carrier signal generation via a pulse generator 


\section{RESULTS AND ANALYSIS}

In order toward authenticating the eleven levels three-phase CHBMLI performance, MATLAB/Simulink environment is fully utilized to simulate planned inverter topology. A reference signal of Sinusoidal and third harmonic injection accompany with bipolar level-shifted, and phase-shifted multicarrier PWM carriers' arrangement is used to yield the switching signals for CHBMLI. For different values of modulation amplitude indices, MA simulations are completed. Analyzed modulation depth extending from $80 \%$ to $100 \%$ modulation depth with a ratio of Modulation Frequency, $M_{f}$ set at 100 . For individual cells, the voltage source is set to regulate at a fixed value of $100 \mathrm{~V}$ with a combination of three-phase series-connected RL load set at $100 \Omega$ and $50 \mathrm{mH}$. To each leg of CHBMLI, with existing of SPWM and THIPWM reference signal, parameters such RMS phase voltage line-to-neutral $\left(\mathrm{V}_{\mathrm{RMS}}\right)$, crest factor $(\mathrm{CF})$, form factor $(\mathrm{FF})$, Phase Voltage and Phase Current $\% \mathrm{THD}_{\mathrm{V}}$ and $\% \mathrm{THD}_{\mathrm{I}}$ is evaluated. Figure 2(a) and Figure 2(b) displays the threephase waveform of output voltage for the CHBMLI by SPWM and THIPWM reference signal technique at $M_{a}=1$ using level-shifted multicarrier PWM techniques (LSPWM). Meanwhile, the three-phase voltage output waveform for CHBMLI through SPWM and THIPWM reference signal technique at $M_{a}=1$ using phase-shifted multicarrier PWM techniques (PSPWM) is as shown in Figure 3(a) and Figure 3(b). For both carrier arrangement strategy, the same structure of each output phase voltage waveform is seen when simulated via SPWM or THIPWM. Therefore, to recognize the substantial difference among LSPWM and PSPWM carrier arrangement, further deeper analysis is carried out.

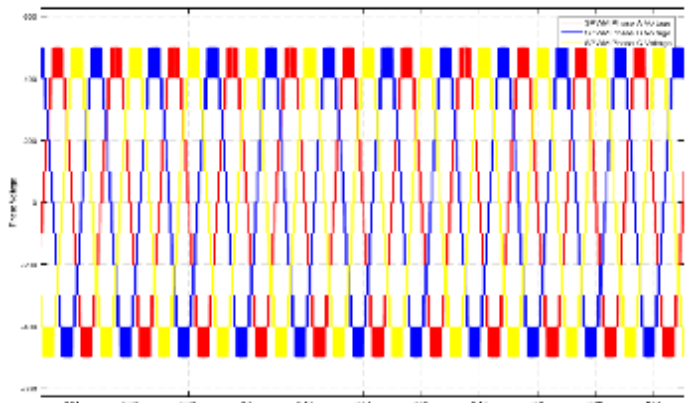

(a)

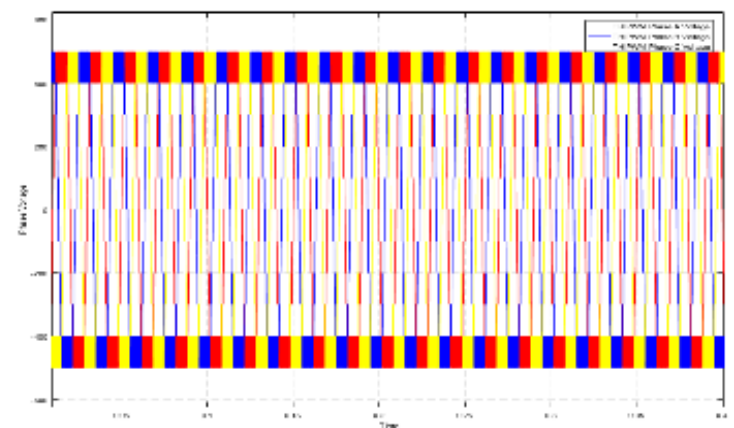

(b)

Figure 2. Output voltage waveform three-phase eleven level CHBMLI with LSPWM carrier arrangement via, (a) SPWM, (b) THIPWM

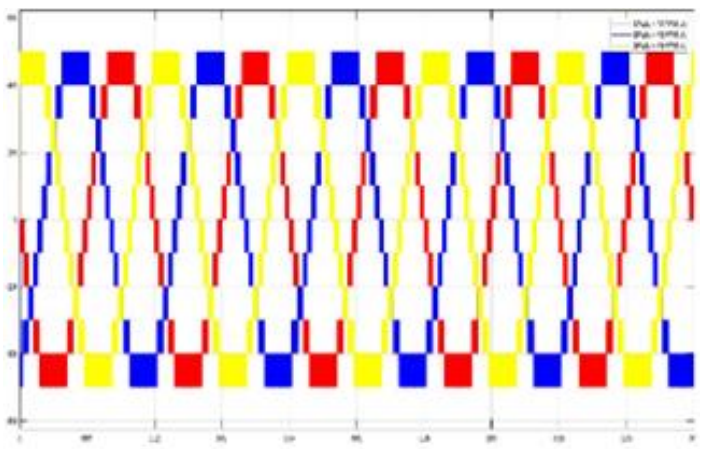

(a)

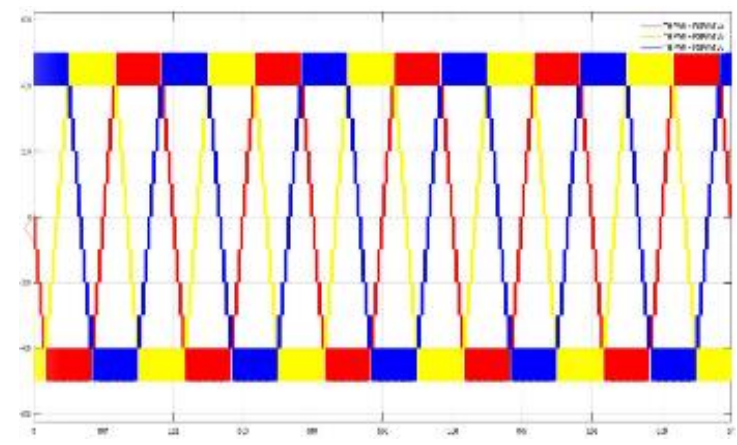

(b)

Figure 3. Output voltage waveform three-phase eleven level CHBMLI with PSPWM carrier arrangement via, (a) SPWM, (b) THIPWM

Based on the previous study conducted for CHBMLI with LSPWM carrier signal arrangement, Phase Disposition carrier signal revealed, at $100 \%$ modulation depth, it is far improved compared to POD and APOD carrier signal arrangement [14]. Therefore, to simplified analysis and determine the important difference among LSPWM and PSPWM carrier arrangement, PD carrier signal arrangement is chosen to be compared with the PSWPM carrier signal arrangement. By tabulated data captured from MATLAB/Simulink environment, Figure 4(a) exhibits the phase voltage, $\mathrm{V}_{\mathrm{RMS}}\left(\mathrm{V}_{\mathrm{a}}, \mathrm{V}_{\mathrm{b}}\right.$, and $\left.\mathrm{V}_{\mathrm{c}}\right)$ when the CHBMLI simulated

Analysis on three phase cascaded h-bridge multilevel inverter based on ... (A. Shamsul Rahimi A. Subki) 
using LSPWM (LSPD) and PSPWM carrier strategy with SPWM reference signal at $80 \%$ to $100 \%$ modulation depth. Based on data gathered, when using the same reference signal, the values of $\mathrm{V}_{\mathrm{RMS}}$ is not varied excessively form one another. Nevertheless, Figure 4(b) shown, when then CHBMLI is simulated using the THIPWM reference signal, the phase voltage, $\mathrm{V}_{\mathrm{RMS}}$ is $5 \%$ higher when using LSPWM compared to PSPWM. This observation justified that the PDPWM carrier arrangement will produce a higher phase voltage compare to PODPWM, APODPWM, and PSPWM. Further analysis is carried out to determine the difference between SPWM and THIPWM in terms of output voltages.

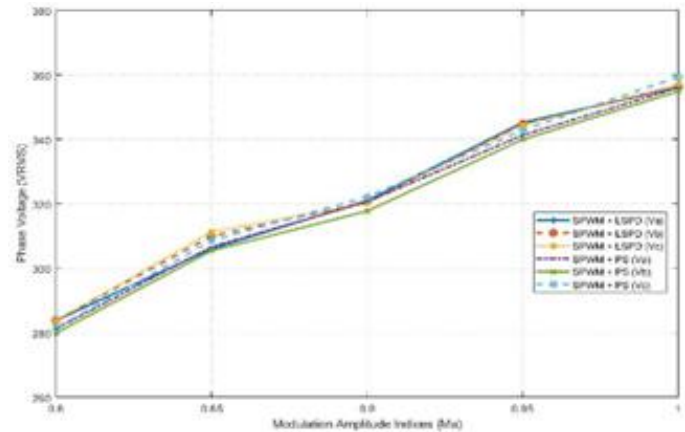

(a)

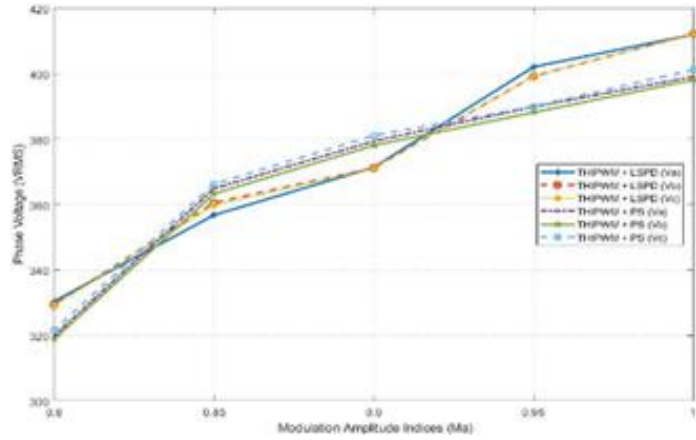

(b)

Figure 4. $\mathrm{V}_{\mathrm{RMS}}\left(\mathrm{V}_{\mathrm{a}}, \mathrm{V}_{\mathrm{b}}\right.$ and $\left.\mathrm{V}_{\mathrm{c}}\right)$ reference at different carrier arrangement strategy at various $M_{a}$ via, (a) SPWM, (b) THIPWM

The output voltage variation for phase-to-neutral voltage among carrier signal with SPWM and THIPWM reference is revealed as in Figure 5. It is observed that the phase voltage, $\mathrm{V}_{\mathrm{A}}$ for CHBMLI simulated via THIPWM reference signal have approximately $15 \%$ greater in peak amplitude value than that registered by the Sinusoidal PWM. This evidence supports previous work that been done by [14]. To conclude, for all reference signal strategy and carrier arrangement control and at full modulation depth, phase-to-neutral voltage is tabulated as in Table 1.

The CHBMLI spectrum of voltage harmonics $\left(\% \mathrm{THD}_{\mathrm{V}}\right)$ simulated using the SPWM reference signal for PD (LSPWM), and PSPWM carrier arrangement strategy is shown in Figure 6 via utilizing fast fourier transform (FFT) [19]. It can observe, based on this spectrum of voltage harmonics, no other harmonic energy produces other than fundamental harmonic with the SPWM reference signal. Through analysis, $\%$ THDV is recorded is $11 \%$ at $100 \%$ modulation depth, for both PD (LSPWM) and PSPWM via the SPWM reference signal. The variation of \% THDV recorded not show substantial different between PD (LSPWM) and PSPWM carrier arrangement. The difference of \% THDV across analyzed modulation depth for LSPWM and PSPWM carriers' arrangement via the SPWM reference signal is plotted as in Figure 7.

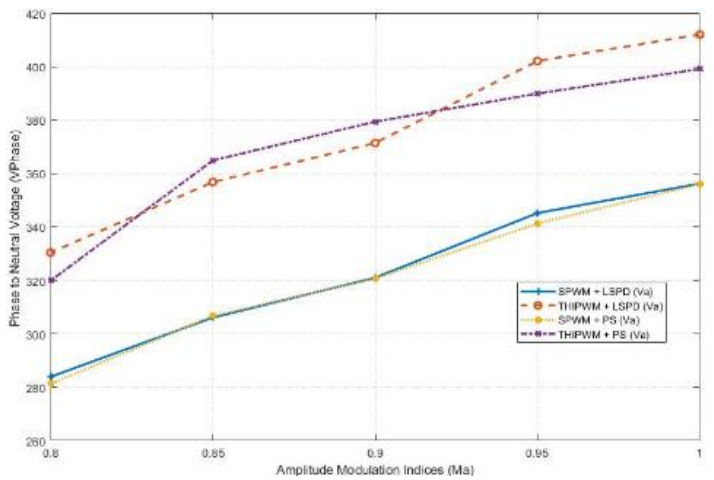

Figure 5. Output voltage variation for phase to neutral between LSPD and PSPWM via SPWM and THIPWM 
Table 1. Voltage for phase to neutral at $100 \%$ modulation depth

\begin{tabular}{ccccc}
\hline PWM Technique & Carrier Strategy & $\mathrm{V}_{\text {RMS }}\left(\varphi_{\mathrm{A}}\right)$ & $\mathrm{V}_{\text {RMS }}\left(\varphi_{\mathrm{B}}\right)$ & $\mathrm{V}_{\text {RMS }}\left(\varphi_{\mathrm{C}}\right)$ \\
\hline \multirow{4}{*}{ SPWM } & PD & 356.2 & 356.3 & 357.1 \\
& POD & 355.6 & 350 & 352 \\
& APOD & 363.5 & 355.5 & 359.7 \\
& PS & 356 & 354.9 & 359.4 \\
\multirow{5}{*}{ THIPWM } & PD & 412 & 412.2 & 412.2 \\
& POD & 398.2 & 399.9 & 399.6 \\
& APOD & 401.3 & 400.9 & 401.4 \\
& PS & 399.1 & 398.1 & 401.2 \\
\hline
\end{tabular}

The CHBMLI spectrum of voltage harmonic $\left(\% \mathrm{THD}_{\mathrm{V}}\right)$ simulated using the THIPWM reference signal for PD (LSPWM), and PSPWM carrier arrangement strategy is shown in Figure 8. According to the spectrum of voltage harmonics, it can be realized, other than fundamental harmonic, a significant $3^{\text {rd }}$ harmonic energy is produced. $\% \mathrm{THD}_{\mathrm{V}}$ recorded is $18.5 \%$ at $100 \%$ modulation depth for simulated PD (LSPWM) and PSPWM strategy of carrier arrangement. Between carrier arrangements, not any significant differences observed based on the variation of \% THDV recorded. The difference of \% THD $\mathrm{V}$ across analyzed modulation depth for PD (LSPWM) and PSPWM carriers' arrangement through the THIPWM reference signal is plotted as in Figure 9. At amplitude modulation indices equal to 0.9, for all LSPWM and PSPWM carrier arrangement, the maximum $\% \mathrm{THD}_{\mathrm{v}}$ recorded. Figure 10 shows the comparison of phase voltage total harmonic distortion, \% THD $\mathrm{T}_{\mathrm{V}}$ across analyzed modulation depth for PD (LSPWM) and PSPWM carriers' arrangement through SPWM and THIPWM reference signal. To conclude, the recorded \% THD v using the SPWM reference signal is lower compare to $\% \mathrm{THD}_{\mathrm{V}}$ recorded via the THIPWM reference signal due to the lower output fundamental voltage component recorded [14].

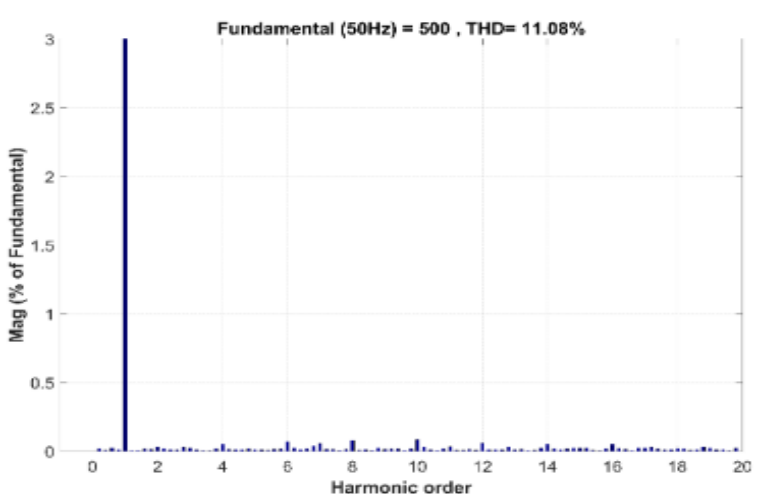

(a)

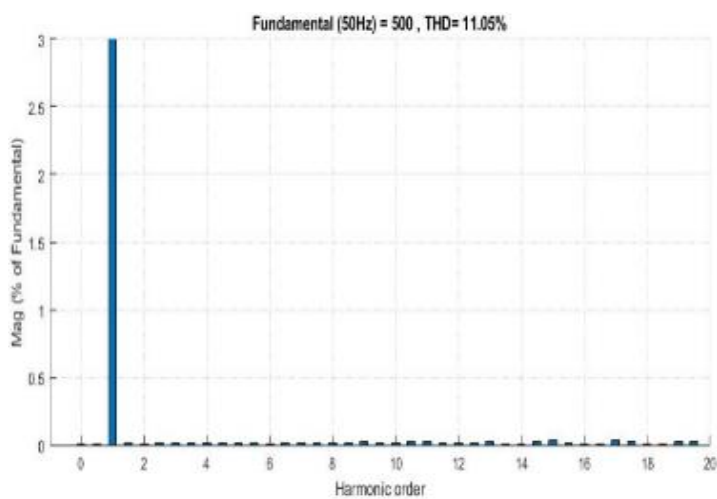

(b)

Figure 6. \% $\mathrm{THD}_{\mathrm{V}}$ among carrier signal through SPWM reference signal, (a) PD (LSPWM), (b) PSPWM

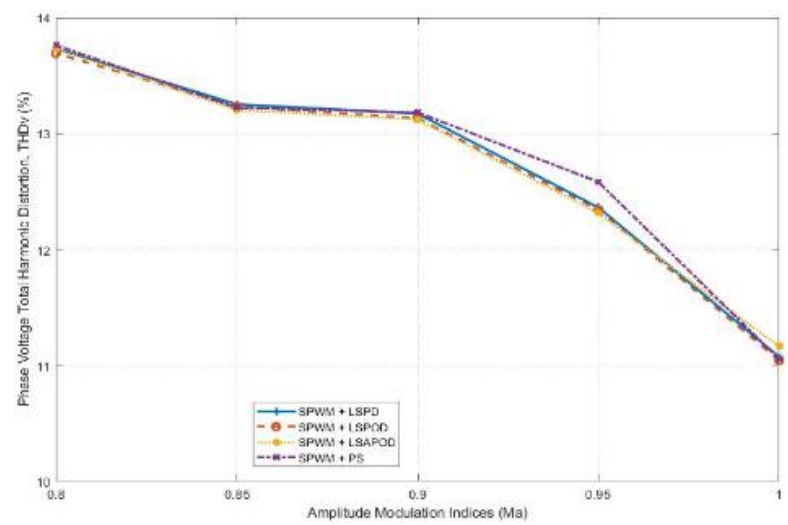

Figure 7. \% THD $\mathrm{V}$ variation for LSPWM and PSPWM carrier's arrangement strategy 


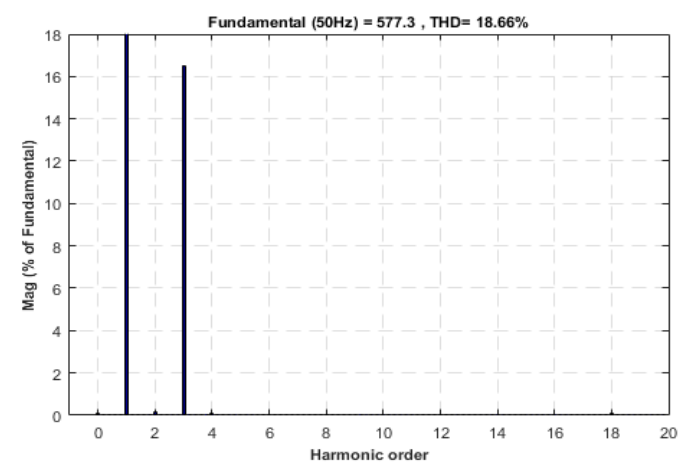

(a)

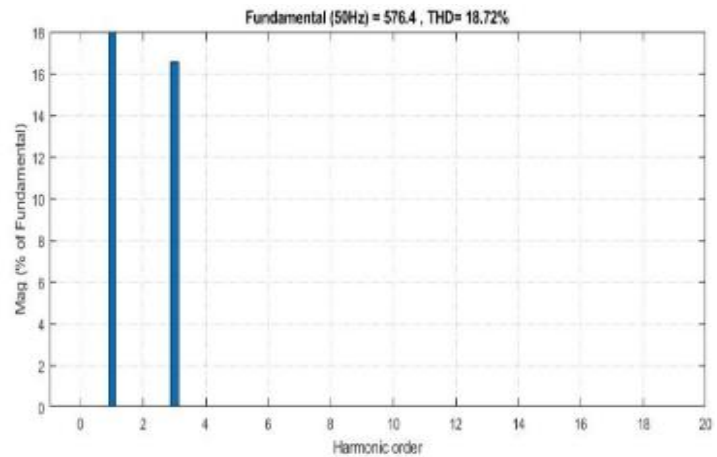

(b)

Figure 8. \% THDV among carrier signal through THIPWM reference signal, (a) PD (LSPWM), (b) PSPWM

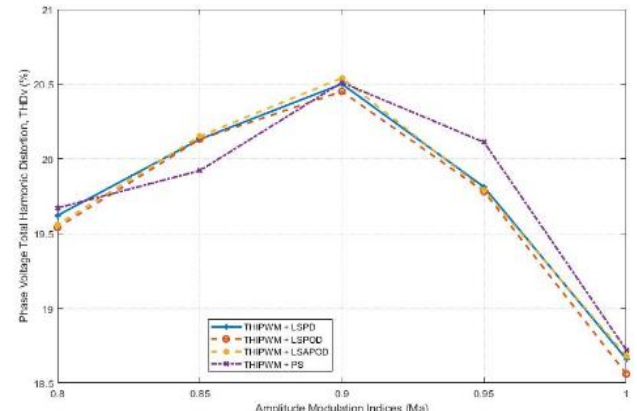

Figure 9. \% $\mathrm{THD}_{\mathrm{V}}$ variation for LSPWM and PSPWM carrier's arrangement strategy

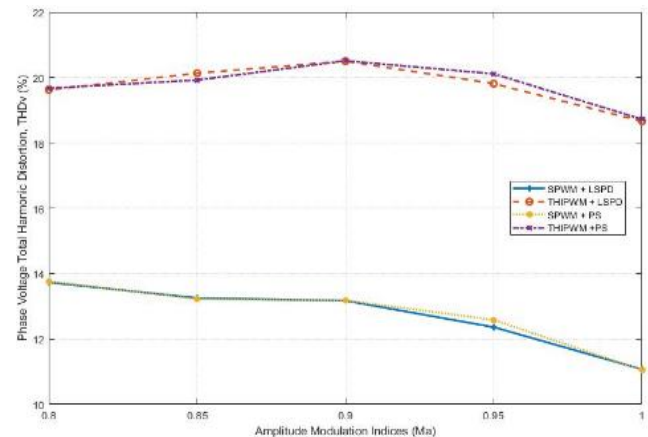

Figure 10. Comparison of \% THDv for PD (LSPWM) and PSPWM carrier's arrangement through SPWM and THIPWM reference signal

Another fascinating performance parameter that can be compared between LSPWM and PSPWM is the current total harmonic distortion $\left(\% \mathrm{THD}_{\mathrm{I}}\right)$. Therefore, an analysis conducted to determine the significant variance when CHBMLI is fed from SPWM and THIPWM reference signal. Hence, Figure 11(a) shows the comparison of current total harmonic distortion, \% $\mathrm{THD}_{\mathrm{I}}$ across analyzed modulation depth for all LSPWM and PSPWM carriers' arrangement through the SPWM reference switching method. From the data gathered and analyzed, $\% \mathrm{THD}_{\mathrm{I}}$ is significantly improved when CHBMLI utilized PSPWM carrier arrangement strategy. It is recorded that via LSPWM, \% THD I tabulated around $2.3 \%$ compared to $0.2 \%$ via PSPWM at $100 \%$ modulation depth. Meanwhile, there is no significant difference in terms of $\% \mathrm{THD}_{\mathrm{I}}$ when CHBMLI is simulated using THIPWM. Figure 11(b) shows the comparison of current total harmonic distortion, $\%$ THD $_{\text {I }}$ across analyzed modulation depth for all LSPWM and PSPWM carriers' arrangement through the THIPWM reference switching method. However, $\% \mathrm{THD}_{\mathrm{I}}$ is recorded to have stable value across analyzed modulation depth via PSPWM.

To measure the low-frequency signals, crest factor $(\mathrm{CF})$ is a decisive parameter. Crest factor $(\mathrm{CF})$ is defined as a fraction of the waveform's peak amplitude value to its RMS value [14]. The sole purpose for CF determination is to quickly recognize how much impact has occurred in the waveform [3]. To achieve a perfectly sinusoidal waveform, CF ratio value gained must are equal or close to the square root of 2 . Thus, the CF analysis for LSPWM and PSPWM carrier arrangement simulated via SPWM reference signal switching technique with range across analyzed modulation depth is as shown in Figure 12(a). In the meantime, Figure 12(b) shows the analysis for LSPWM and PSPWM carrier arrangement simulated via the THIPWM reference signal switching technique with range across analyzed modulation depth. According to Figure 12(a) and 12(b) at full depth of modulation, for equally SPWM and THIPWM reference signal technique, PD (LSPWM) carrier arrangement strategy provide a CF documented near to perfect square root of 2 value.

Normally, to quantify the shape of output voltage, the value of form factor (FF) is used [25]. The assessment for both reference signal switching scheme in term of FF for LSPWM and PSPWM carrier arrangement across analyzed modulation depth is shown in Figure 13. Based on our analysis, at 100\% 
modulation depth, FF is captured nearly perfect for SPWM reference signal switching technique accompany with PD (LSPWM) and PSPWM carrier's arrangement. For THIPWM, it is recorded to yield the closed FF ratio through PD (LSPWM) carrier arrangement.

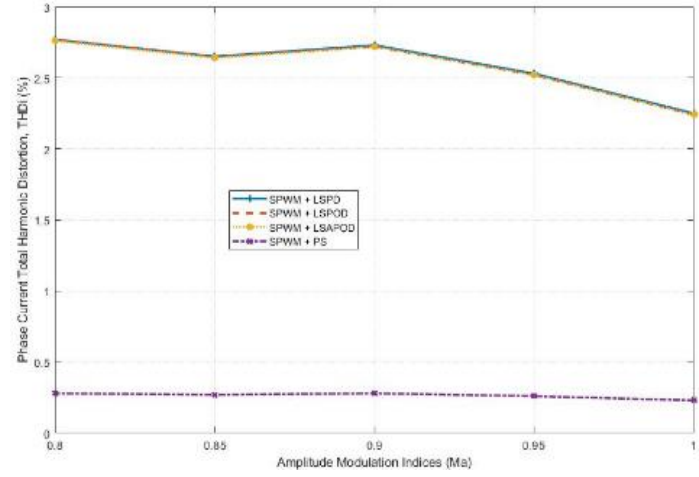

(a)

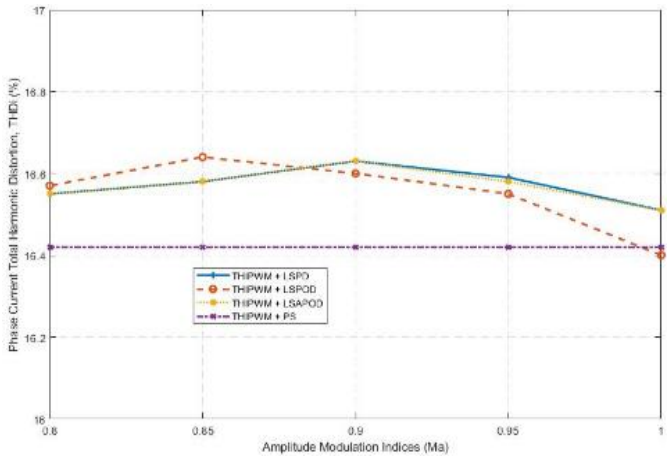

(b)

Figure 11. Comparison of $\% \mathrm{THD}_{\mathrm{I}}$ across LSPWM and PSPWM carrier's arrangement reference signal via, (a) SPWM, (b) THIPWM

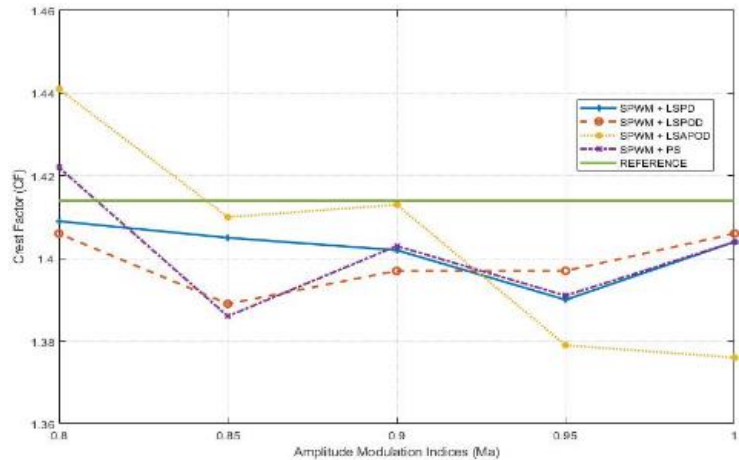

(a)

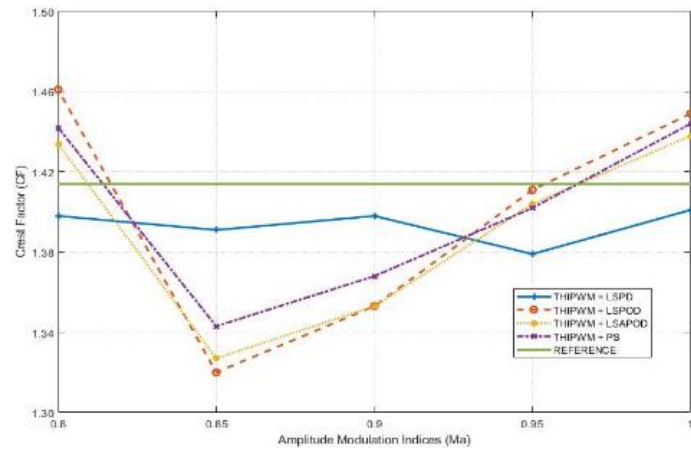

(b)

Figure 12. Crest factor for output voltage via LSPWM and PSPWM carrier arrangement with different switching technique, (a) SPWM, (b) THIPWM

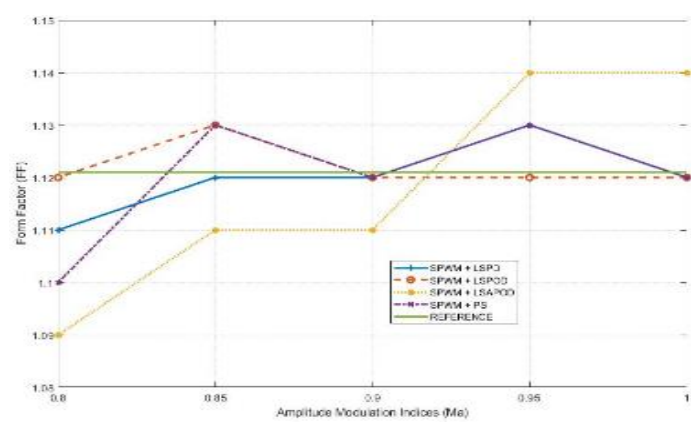

(a)

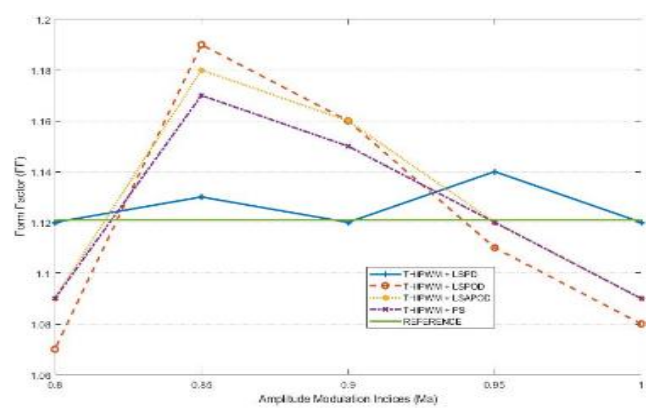

(b)

Figure 13. Form Factor comparison among LSPWM and PSPWM carrier's arrangement via, (a) SPWM, (b) THIPWM

\section{CONCLUSION}

Via SIMULINK environment three phase CHBMLI, 11 levels with R-L load utilizing sinusoidal and third harmonic injection PWM reference signal switching strategy has been established, simulated and 
analyzed. PD (LSPWM) and PSPWM control methods are implemented and compared with an identical simulation parameter, and Ma rose from $80 \%$ to $100 \%$ modulation depth. According to the analyzed result, the performance is acceptable in terms of \% THDV and \% THDI values. Simulation analysis also indicates, at full modulation depth, due to higher fundamental output voltage component produces via the THIPWM modulation technique compared to the SPWM technique, this causes higher \%THDV. Therefore, to authenticate the result of simulation analysis, extensive work, particularly involving hardware implementation, needs to be conducted.

\section{ACKNOWLEDGEMENTS}

FTKEE with full support from UTeM thanked for financing and sponsoring this study via PJP/2019/ FTKEE (4B)/S01656 short-term grant.

\section{REFERENCES}

[1] B. Shanthi and S. P. Natarajan, "Comparative study on unipolar multicarrier PWM strategies for five-level flying capacitor inverters," 2009 International Conference on Control, Automation, Communication and Energy Conservation, Perundurai, Tamilnadu, 2009, pp. 1-7.

[2] Colak I., Kabalci E., and Bayindir R., "Review of multi-level voltage source inverter topologies and control schemes," Energy Convers and Management, vol. 52, no. 2, pp. 1114-1128, 2011.

[3] O. Salama, A. Tabyaoui, and M. Benchagra, "Control Methods on Three-phase Power Converters in Photovoltaic Systems," International Journal of Power Electronics and Drive System (IJPEDS), vol. 9, no. 4, pp. 1851-1865, 2018.

[4] H. Hasabelrasul and X. Yan, "Comparison of multicarrier PWM techniques for cascaded H-bridge multi-level inverter," International Journal of Power Electronics and Drive System (IJPEDS), vol. 8, no. 2, pp. 861-868, 2017.

[5] Muhammad T. et al., "Cascaded Symmetric Multilevel Inverter with Reduced Number of Controlled Switches," International Journal of Power Electronics and Drive System (IJPEDS), vol. 8, no. 2, pp. 795-803, 2017.

[6] N. Celanovic and D. Boroyevich, "A fast space-vector modulation algorithm for multi-level three-phase converters," in IEEE Transactions on Industry Applications, vol. 37, no. 2, pp. 637-641, 2001.

[7] J. Joseph and A. Prakash, "Cascaded multi-level inverter with multicarrier PWM techniques," International Journal of Engineering Science \& Advanced Technology, vol. 4, no. 5, pp. 437-442, 2014.

[8] A. S. R. A. Subki, M. Z. M. Tumari, W. N. A. Rashid, A. Z. Jidin, and A. N. M. Mustafa, "Hardware implementation of single phase three-level cascaded H-bridge multi-level inverter using sinusoidal pulse width modulation," International Journal of Power Electronics and Drive System (IJPEDS), vol. 10, no. 2, pp. 625-635, 2019.

[9] L. Nanda, A. Dasgupta, and U. K. Rout, "A comparative Analysis of Symmetrical and Asymmetrical Cascaded Multilevel Inverter Having Reduced Number of Switches and DC Sources," International Journal of Power Electronics and Drive System (IJPEDS), vol. 8, no. 4, pp. 1595-1602, 2017.

[10] N. Prabaharan and K. Palanisamy, "A comprehensive review on reduced switch multi-level inverter topologies, modulation techniques and applications," Renewable and Sustainable Energy Reviews, vol. 76, pp. 1248-1282, 2017.

[11] Tsunoda A., Hinago Y., and Koizumi H., "Level- and phase-shifted PWM for seven-level switched-capacitor inverter using series/parallel conversion," IEEE Transactions on Industrial Electronics, vol. 61, no. 8, pp. 4011-4021, 2014.

[12] Carrara G., Gardella S., Marchesoni M., Salutari R., and Sciutto G., "A new multi-level PWM method: a theoretical analysis," IEEE Transactions on Power Electronics, vol. 7, no. 3, pp. 497-505, 1992.

[13] Hiyagarajan V. and Somasundaram P., "A New Seven Level Symmetrical Inverter with Reduced Switch Count," International Journal of Power Electronics and Drive System (IJPEDS), vol. 9, no. 2, pp. 921-925, 2018.

[14] Naderi R. and Rahmati A., "Phase-shifted carrier PWM technique for general cascaded inverters," IEEE Transactions on Power Electronics, vol. 23, no. 3, pp. 1257-1269, 2008.

[15] Zhao J., He X., and Zhao R., "A novel pwm control method for hybrid-clamped multi-level inverters," IEEE Transactions on Industrial Electronics, vol. 57, no. 7, pp. 2365-2373, 2010.

[16] Alexander S. A., "Development of solar photovoltaic inverter with reduced harmonic distortions suitable for Indian sub-continent," Renewable and Sustainable Energy Reviews, vol. 56, pp. 694-704, 2016.

[17] Y. Babkrani, A. Naddami, and M. Hilal, "A smart cascaded H-bridge multi-level inverter with an optimized modulation technique increasing the quality and reducing harmonics," International Journal of Power Electronics and Drive System (IJPEDS), vol. 10, no. 4, pp. 1852-1862, 2019.

[18] A. S. R. A. Subki, M. Z. Tumari, N. M. Yusof, A. Z. Jidin, A. F. Z. Abidin, W. N. A. Rashid, M. S. Saealal, and A. W. Ab Aziz, "Comparative study of sinusoidal PWM and third harmonic injected PWM on three phase cascaded H-bridge multi-level inverter at various amplitude modulation indices," 2018 IEEE PES Asia-Pacific Power and Energy Engineering Conference (APPEEC), Kota Kinabalu, 2018, pp. 520-525.

[19] C. R. Balamurugan, S. P. Natarajan, R. Bensraj, and B. Shanthi, "A review on modulation strategies of multi-level inverter," Indonesian Journal of Electrical Engineering and Computer Science (IJEECS), vol. 3, no. 3, pp. 681-705, 2016. 
[20] Balamurugan C. R., Natarajan S. P., and Padmathilagam V., "Comparative study on various bipolar pwm strategies for three phases five level cascaded inverter," ARPN Journal of Engineering and Applied Sciences, vol. 7, no. 9, pp. 1091-1101, 2012.

[21] T. P. Kakosimos, K. Pavlou, A. Kladas, and S. Manias, "A single-phase nine-level inverter for renewable energy systems employing model predictive control," Energy Conversion and Management, vol. 89, pp. 427-437, 2015.

[22] M. Coppola, F. Di Napoli, and P. Guerriero, "An FPGA-Based Advanced Control Strategy of a Grid-Tied PV CHB Inverter," IEEE Transactions on Power Electronics, vol. 31, no. 1, pp. 806-816, 2016.

[23] S. V. Madhavi and G. T. R. Das, "Comparative Study of Controllers for an Isolated Full Bridge Boost Converter Topology in Fuel Cell Applications," International Journal of Power Electronics and Drive System (IJPEDS), vol. 9, no. 4, pp. 1644-1656, 2018.

[24] M. Khanfara, R. El Bachtiri, M. Boussetta, and K. El Hammoumi, "A Multicarrier PWM Technique for Five Level Inverter Connected to the Grid," International Journal of Power Electronics and Drive System (IJPEDS), vol. 9, no. 4, pp. 1774-1783, 2018.

[25] G. V. Krishnan, M. V. Rajkumar, and C. Hemalatha, "Modeling and Simulation of 13-level Cascaded Hybrid Multilevel Inverter with less number of Switches," International Journal of Innovative Studies in Sciences and Engineering Technology ISSN 2455-4863 (IJISSET), vol. 2, no. 11, pp. 43-47, 2016. 